\title{
Anticancer Attributes of Gold Nanoparticles Synthesized by Novel Isolate Streptomyces tuirus DBZ39
}

\author{
Bi Bi Zainab Mazhari*1, Dayanand Agsar ${ }^{2}$, Mohammed H Saiemaldahr ${ }^{1}$, Waleed Abu AlSoud ${ }^{1}$, Ahmad Adam ${ }^{1}$, Amina \\ Qaeet Alrowaily ${ }^{\mathbf{1}}$ and Intisar Elshek ${ }^{1}$ \\ ${ }^{1}$ Department of Microbiology, Jouf University, Saudi Arabia \\ ${ }^{2}$ Department of Microbiology, Gulbarga University, India
}

Received: 制: September 16, 2018; Published: 制 September 20, 2018

*Corresponding author: Bi Bi Zainab Mazhari, Department of Microbiology, Jouf University, Al Jouf, Saudi Arabia

\begin{abstract}
In the present investigation, an attempt was made to explore the anticancer activity of extracellular gold nanoparticles from Streptomyces sp. The synthesized gold nanoparticles were characterized by UV-vis spectrophotometry and scanning electron microscopy. The presence of gold nanoparticles after the synthesis was examined by recording the UV-vis spectra of the solution and also by visual biomonitoring of the solution. The peaks recorded in the UV-vis spectra of the solutions was in between the wavelength of 500 to $600 \mathrm{~nm}$ which confirms the presence of gold nanoparticles. Scanning electron microscopy reveals the synthesis of gold nanoparticles with an average size 27 to $56 \mathrm{~nm}$ in the solution. Different

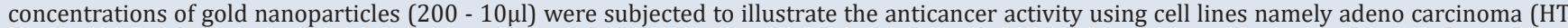
29), kidney cancer (K 293) and breast cancer (MDA 231). The percent inhibition for these cell lines was recorded and observed to be very high at $200 \mu \mathrm{l}$. The investigation revealing the anticancer activity of gold nanoparticles has been reported for the first time. Gold nanoparticles could be used as cost effective and efficient means of future devices in medical sciences.
\end{abstract}

Keywords: Streptomyces; Gold nanoparticles; Anticancer; Cell lines

\section{Introduction}

In modern scenario nanotechnology is used to provide more accurate and timely medical information for diagnosing and treating human cancers. Cancers is a complex disease occurring as a result of a progressive accumulation of genetics and epigenetics changes that unable escape from normal cellular and environmental control [1-3]. Cancer is the leading cause worldwide [4]. Traditionally the most common cancer treatment was limited to chemotherapy radiation and surgery. Limitations in cancer treatment are result of current challenges which leads to the development of cancer therapies including lack of early disease detection, nonspecific systemic distribution, in adequate drug concentration reaching the tumor and ability to monitor therapeutic responses [5]. Many attempts have been made to use silver nanoparticles as an anticancer agent and they have all turned up positive [6].

The role of gold nanoparticles as an anticancer agent should open new doors in the field of medicine [7]. In view of this an attempt was made to focus on the role of microbially synthesized gold nanoparticles in cancer diagnosis and therapy. The present study was carried out to prove the anticancer action of gold nanoparticles synthesized using Streptomyces tuirus DBZ39 on Adenocarcinoma (HT 29), Kidney cancer (K 293) and breast cancer
(MDA 231) evaluating the number of viable cells after incubation with the microbially synthesized extracellular gold nanoparticles at different concentrations and duration of exposure.

\section{Materials and Methods}

\section{Biosynthesis of extracellular gold nanoparticles}

An isolate of Streptomyces tuirus DBZ39 obtained from limestone quarry soil earlier was employed for the synthesis of extracellular gold nanoparticles, as per the standard protocol [68]. A loopful of three days old culture of Streptomyces tuirus DBZ39 was inoculated into starch casein broth containing Starch-1g, casein-0.003g, $\mathrm{KH}_{2} \mathrm{PO}_{4}-2.0 \mathrm{~g}, \mathrm{KNO}_{3}-2.0 \mathrm{~g}, \mathrm{NaCl}-2.0 \mathrm{~g}, \mathrm{MgSO}_{4}-0.002 \mathrm{~g}$, $\mathrm{FeSO}_{4}-0.001 \mathrm{~g}, \mathrm{CaCo}_{3}-0.001 \mathrm{~g}$ and incubated at $400 \mathrm{C}$ for 5 days on rotatory shaker (200rpm). After incubation, the broth culture was centrifuged at $8000 \mathrm{rpm}$. The biomass obtained was suspended in Aurium Chloride $\left(\mathrm{AuCl}_{4}\right)$ solution and kept for incubation at $370 \mathrm{C}$ on shaker (200rpm) for three days. The gold nanoparticles synthesized in the solution were visually confirmed by the development of deep purple colour and UV-visible absorption spectrum in the range of $500-550 \mathrm{~nm}$. The gold nanoparticles produced were characterized by Scanning electron microscopy for their size, shape and dispersion as per the standard protocols $[9,10]$. 


\section{Anticancer activity of gold nanoparticles}

Anticancer activity of gold nanoparticles was carried out by following the standard procedure prescribed by Marques-Gallego et al., [11]

\section{Preparation of cell lines}

HT-29 (human adeno carcinoma), K-293 (human kidney), MDA231 (human breast cancer) cell lines were grown as adherent in DMEM media, whereas MCF-7 (Breast cancer lines) were grown in MEM media supplemented with $10 \%$ fetal bovine serum, $100 \mu \mathrm{g} / \mathrm{ml}$ penicillin, $200 \mu \mathrm{g} / \mathrm{ml}$ Streptomycin, $2 \mathrm{~mm}$ L-glutamine and culture was maintained in a humidified atmosphere with $5 \% \mathrm{CO}_{2}$.

\section{Preparation of samples for cytotoxicity}

Stock solution of $10 \mathrm{mg} / \mathrm{ml}$ stock solution in DMSO, from the above stock was made with sterile water to get required concentration.

\section{Cytotoxicity evaluation}

Toxicity of test compound in cells was determined by MTT assay based on mitochondrial reduction of yellow MTT tetrazdium dye to highly coloured blue formazen product. $1 \times 104$ cells (counted by Trypan exclusion dye method) in 96 well plates were incubated with compounds with series of concentrations tested for $48 \mathrm{hrs}$ at 370C in DMEM/MEM with 10\% FBS medium. Then the above media was replaced with $90 \mu \mathrm{l}$ of fresh serum free media and $10 \mu \mathrm{l}$ of MTT reagent $(5 \mathrm{mg} / \mathrm{ml})$ and plates were incubated at $370 \mathrm{C}$ for $4 \mathrm{hrs}$, thereafter the above media was replaced with $200 \mu \mathrm{l}$ of DMSO and incubated at $370 \mathrm{C}$ for $10 \mathrm{~min}$. The absorbance at $570 \mathrm{~nm}$ was measured on a spectrophotometer (spectra mass, molecular devices) IC-50 values were determined from plot: \% inhibition (from control) Vs Concentration [11-13].

\section{Results}

\section{Biosynthesis of extracellular gold nanoparticles}

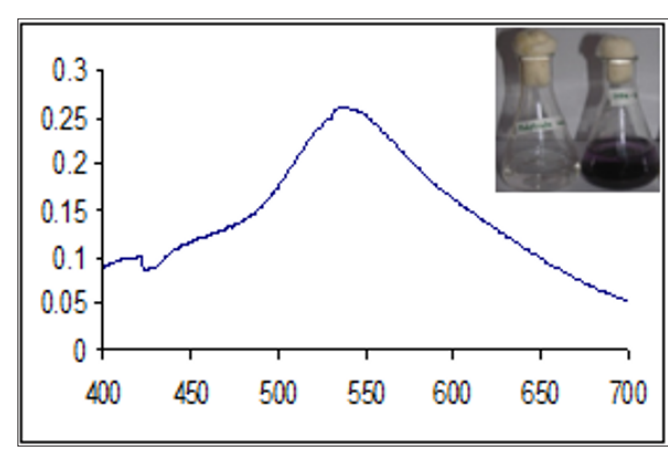

Figure 1: Visual observation and UV-vis absorbance spectra of gold nanoparticles synthesized by Streptomyces tuirus DBZ39.

Synthesis of gold nanoparticles was carried out by Streptomyces tuirus DBZ39 as explained earlier under materials and methods. The presence of gold nanoparticles after the synthesis was examined by recording the UV-vis spectra of the solution and also by visual biomonitoring of the solution. The peaks recorded in the UV-vis spectra of the solutions was in between the wavelength of 500 to
$600 \mathrm{~nm}$ confirms the presence of gold nanoparticles (Figure 1). The development of deep red colour uniformly throughout the solution was recorded as extracellular synthesis (Figure 1). Nanoparticles composed of gold offer, in addition to their enhanced absorption and scattering, good biocompatibility, facile synthesis and conjugation to a variety of biomolecular ligands, antibodies and other targeting moieties, making them suitable for use of biochemical sensing and detection, medical diagnostic and therapeutic applications [14-21].

There have been several demonstrations of bioaffinity sensors based on the plasmon absorption and scattering of nanoparticles and their assemblies [23]. UV, XRD, EDAX and electron microscopic (SEM and TEM) studies are important and normally employed for the detection and characterization of nanoparticles. In the present study, Scanning Electron Microscopy is employed to detect and characterize the extracellular gold nanoparticles synthesized by Streptomyces tuirus DBZ39. Scanning electron microscopy of gold nanoparticles produced by Streptomyces tuirus DBZ39 is presented in Figure 2. Production of spherical nanoparticles with an average size of 27-56 nm of were observed.

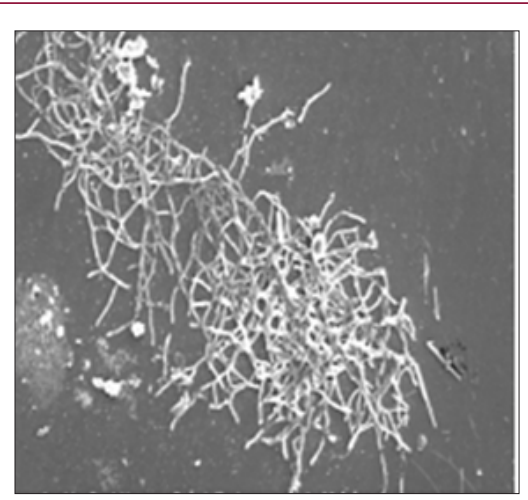

Figure 2: Scanning electron Microscopy of gold nanoparticles synthesized by Streptomyces tuirus DBZ39.

\section{Anticancer activity of gold nanoparticles}

The development of nanobiotechnology has progressed by leaps and bounds. Engineered and desired nanoparticles have been mass produced microbially and are being widely applied as commercial and emerging biomedical agents. Despite the rapid progress and earlier acceptance of microbial nanotechnology, the potential for adverse health effects due to short and long term exposure has not yet being established. However, gold nanoparticles acting on the living cells at nanolevel resulting not only is biologically desirable, but also generates undesirable affects. Though, many effects of gold nanoparticles have been aimed at exploiting beneficial properties for various purposes, there are limited attempts to evaluate the probable ill effects of these materials. Therefore, it is necessary that, the safety of newly synthesized gold nanoparticles that influence their associated hazards are understood.

An important area governing regulatory health risk assessment is carcinogenicity of gold nanoparticles. In view of this, gold nanoparticles with a size of 27 to $56 \mathrm{~nm}$, at different concentrations were used to know the anticancer activity against different cell lines. Different cell lines to study the anticancer activity of gold 
nanoparticles, namely adeno carcinoma (HT 29), kidney cancer (K 293) and breast cancer (MDA 231) were subjected at different concentrations $(200-10 \mu \mathrm{l})$ of gold nanoparticle solution. The percent inhibition of all the three cell lines was recorded and observed to be very high at $200 \mu \mathrm{l}$ concentrations (Table 1). The anticancer activity of kidney cancer cell lines (K - 293) recorded to be significantly very high with high IC50 value 139 (Figure 3). Nano medicine concerns the use of precision - engineered nanoparticles to develop novel anticancer therapeutic agents for human use. The present report demonstrates the efficacy of gold nanoparticles synthesized by Streptomyces as an anticancer agent.

Table 1: Anticancer activity of gold nanoparticles synthesized by Streptomyces tuirus DBZ39 against different cell lines.

\begin{tabular}{|c|c|c|c|c|c|c|c|c|c|c|}
\hline $\begin{array}{l}\text { Material } \\
\text { code }\end{array}$ & \multicolumn{2}{|c|}{$\begin{array}{l}\text { HMDA231 (human } \\
\text { breast cancer) }\end{array}$} & $\begin{array}{c}\% \\
\text { Inhibition }\end{array}$ & IC $_{50}$ values & $\begin{array}{c}\text { H } \\
\text { T29 (human } \\
\text { adeno }\end{array}$ & $\begin{array}{c}\% \\
\text { Inhibition }\end{array}$ & $\begin{array}{c}\mathrm{IC}_{50} \\
\text { values }\end{array}$ & $\begin{array}{l}\text { K293 } \\
\text { (human } \\
\text { kidney }\end{array}$ & $\begin{array}{c}\% \\
\text { Inhibition }\end{array}$ & $\begin{array}{c}\mathrm{IC}_{50} \\
\text { values }\end{array}$ \\
\hline \multirow{5}{*}{$\mathrm{Au}$} & $200 \mu \mathrm{l}$ & 0.1975 & 74 & \multirow{5}{*}{100} & 0.13 & 76.57 & \multirow{5}{*}{70.8} & 0.5354 & 57.86 & \multirow{5}{*}{139} \\
\hline & $100 \mu \mathrm{l}$ & 0.2632 & 35.22 & & 0.2551 & 54.37 & & 0.7401 & 41.82 & \\
\hline & $50 \mu \mathrm{l}$ & 0.3064 & 26.28 & & 0.3671 & 34.47 & & 0.9311 & 26.85 & \\
\hline & $25 \mu \mathrm{l}$ & 0.3252 & 22.8 & & 0.4644 & 17.17 & & 1.0411 & 18.23 & \\
\hline & $10 \mu \mathrm{l}$ & 0.3522 & 16.8 & & 0.4757 & 15.16 & & 1.1322 & 11.09 & \\
\hline Control & \multicolumn{4}{|c|}{0.3812} & \multicolumn{3}{|c|}{0.5616} & \multicolumn{3}{|c|}{1.2741} \\
\hline
\end{tabular}

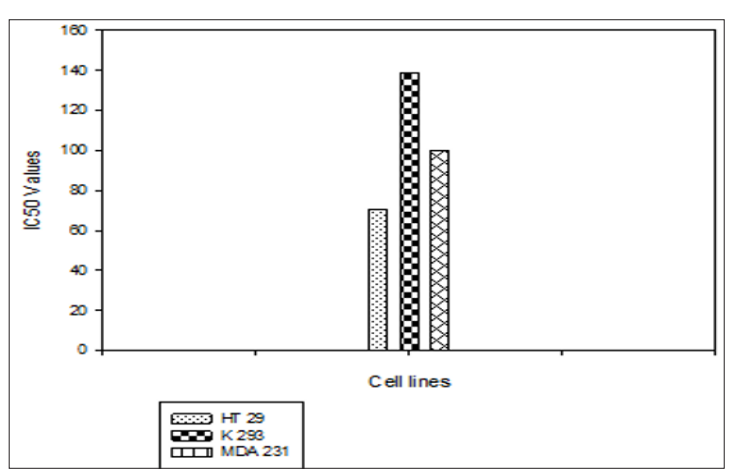

Figure 3: Anticancer activity of gold nanoparticles by Streptomyces tuirus DBZ39 at different $\mathrm{IC}_{50}$ values.

\section{Conclusion}

The novel isolate Streptomyces tuirus DBZ39 prove to be potential for the synthesis of extracellular gold nanoparticles was used to evaluate the anticancer activity at different concentrations. Cell lines namely adeno carcinoma (HT 29), kidney cancer (K 293) and breast cancer (MDA 231) were subjected to test the anticancer activity of gold nanoparticles at different concentrations (200 $10 \mu \mathrm{l})$. The percent inhibition of these cell lines was recorded to be very high at $200 \mu$ l concentrations for kidney cancer cell lines (K 293) with high IC50 value. This investigation reveals notably high anticancer activity of Streptomyces mediated gold nanoparticles at high concentration, which can be considered as good anticancer attribute and promising natural agent against tumor cells which is of important contribution in future for medical therapies.

\section{References}

1. Ahmad A, Mukherjee P, Mandal D, Senapati S, Khan MI, et al. (2002) Enzyme mediated extracellular synthesis of CdS nanoparticles by the fungus, Fusarium oxysporum. J Am Chem Soc 124: 12108-12109.

2. Briendra Kumar, Yadav PR, Goel HC, Moshahid M, Rizvi M (2009) Recent development in cancer therapy by the use of nanotechnology. Digest Journal of nanomaterials and Biostructures 4:1-12.
3. Morones JR, Elechiguerra JL, Camacho A, Holt K, Kouri JB, et al. (2005) The bactericidal effect of silver nanoparticles. Nanotechnology 16: 2346-2353.

4. Sulaimana G, Mohammad AA, Abdul Waheda H, Ismail MM (2013) Biosynthesis, antimicrobial and cytotoxic effects of silver nanoparticles using Rosmarinus officinalis extract. Digest Journal of Nanomaterials and Biostructures 8: 273-280.

5. Vaidyanathan R, Kalishwaralal K, Gopalram S, Gurunathan S (2009) Nanosilver the burgeoning therapeutic molecule and its green synthesis. Biotechnol Adv 27: 924-937.

6. Zainab MB, Madhusudhan DN, Raghavendra H, Dastager SG, Dayanand A (2014) Development of bioconjugate from Streptomyces tyrosinase and gold nanoparticles for rapid detection of phenol constituents. Indian J Exp Biol 25: 1071-1081.

7. Ahmad A, Senapati S, Khan MI, Kumar R, Sastry M (2003) Extracellular biosynthesis of monodisperse gold nanoparticles by a novel extremophilic actinomycete, Thermomonospora sp. Langmuir 19: 35503553.

8. Ahmad A, Senapati S, Khan MI, Kumar R, Ramani R, et al. (2003) Intracellular synthesis of gold nanoparticles by a novel alkalotolerant actinomycete, Rhodococcus species. Nanotechnology 14: 824-828.

9. Krishnaraj C, Jagan EG, Rajasekar S, Selvakumar P, Kalaichelvan PT, et al. (2010) Synthesis of silver nanoparticles using Acalypha indica leaf extracts and its antibacterial activity against water borne pathogens. Colloids Surf B Biointerfaces 76: 50-56.

10. Kowshik M, Ashtaputre S, Kharrazi S, Vogel W, Urban J, et al. (2002) Extracellular synthesis of silver nanoparticles by a silver-tolerant yeast strain MKY3. Nanotechnology 14: 95-100.

11. Marqués-Gallego P, den Dulk H, Backendorf C, Brouwer J, Reedijk J, et al. (2010) Accurate non-invasive image based cytotoxicity assays for cultured cells. BMC Biotechnol 10: 43.

12. Rutberg FG, Dubina MV, Kolikov VA, Moiseenko FV, Ignateva EV, et al. (2008) Effect of silver oxide nanoparticles on tumor growth in vivo. Dokl Biochem Biophys 421: 191-193.

13. Muthu Irulappan Sriram, Selvaraj Barath Mani Kanth, Kalimuthu Kalishwaralal, Sangiliyandi Gurunathan (2010) Antitumor activity of silver nanoparticles in Dalton's lymphoma ascites tumor model. Int J Nanomedicine 5: 753-762.

14. Shipway AN, Lahav M, Willner I (2000) Nanostructured Gold Colloid Electrodes. Adv Mater 12: 993-998. 
15. Bi Bi Zainab Mazhari, Dayanand Agsar, Ambika Prasad MV (2017) Development of paper biosensor for the detection of phenol from industrial effluents using bioconjugate of Tyr-AuNps mediated by novel isolate Streptomyces tuirus DBZ39. J nanomater pp. 8.

16. Bi Bi Zainab Mazhari, Dayanand Agsar (2016) Detection of phenols from industrial effluents using Streptomyces mediated gold nanoparticles. Indian J Mater Sci pp. 5.

17. Bi Bi Zainab Mazhari, Dayanand Agsar (2018) Cytotoxic attribute of extracellular gold nanoparticles mediated by Streptomyces tuirus DBZ39. Int J Creative Res Thought 6: 1374-1391.

18. Bi Bi Zainab Mazhari, Dayanand Agsar (2014) Synthesis, characterization and antimicrobial attributes of gold nanoparticles mediated by NADHdependent nitrate reductase of Streptomyces sp. DBZ-39. J Pure Appli Microbiolo 8(4): 3171-3177.

19. Cole JR, Halas NJ (2006) Optimized plasmonic nanoparticle distributions for solar spectrum harvesting. Appl Phys Lett 89: 153120.

ISSN: 2574-1241

DOI: 10.26717/BJSTR.2018.09.001764

Bi Bi Zainab Mazhari. Biomed J Sci \& Tech Res

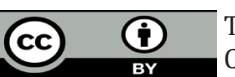

This work is licensed under Creative Commons Attribution 4.0 License

Submission Link: https://biomedres.us/submit-manuscript.php
20. Eustis S, El Sayed MA (2006) Why gold nanoparticles are more prescient than pretty gold: Noble metal surface plasmon resonance and its enhancement of the radiative and nonradiative properties of nanocrystals of different shapes. Chemical Society Reviews 35: 209-217.

21. Hsin YH, Chen CF, Huang S, Shih TS, Lai PS, et al. (2008) The apoptotic effect of nanosilver is mediated by a ROS- and JNK-dependent mechanism involving the mitochondrial pathway in NIH3T3 Cells. Toxicol Lett 179: 130-139.

22. Abraham SA, McKenzie C, Masin D, Harasym TO, Mayer LD, et al. (2004) In-vitro and in-vivo characterization of doxorubicin and vincristine coencapsulated within liposomes through use of transition metal ion complexation and pH gradient loading. J Clin Cancer Res 10: 728-738.

23. Byrd JC, Lucas DM, Mone AP, Kitner JB, Drabick JJ, et al. (2003) KRN5500: A novel therapeutic agent with in-vitro activity against human B-cell chronic lymphocytic leukemia cells mediates cytotoxicity via the intrinsic pathway of apoptosis. Blood 101: 4547-4550.

$\begin{array}{ll}\text { BIOMEDICAL } & \text { Assets of Publishing with us } \\ \text { RESEARCHES } & \text { - Global archiving of articles } \\ & \text { - Immediate, unrestricted online access } \\ & \text { - Rigorous Peer Review Process } \\ & \text { - Authors Retain Copyrights }\end{array}$

